\title{
IDENTIFICATION OF DROUGHT-FLOOD ABRUPT ALTERNATION IN TOBACCO GROWTH PERIOD IN XINGREN COUNTY UNDER CLIMATE CHANGE IN CHINA
}

\author{
ZHANG, Z. Z. ${ }^{1}-$ YUAN, Y. J. ${ }^{*}-$ SHEN, D. F. ${ }^{2}-$ FAN, H. ${ }^{1}$ \\ ${ }^{1}$ School of water conservancy engineering, North China University of Water Resources and \\ Electric Power, Zhengzhou 450046, China \\ ${ }^{2}$ Guizhou Water Conservancy Research Institute, Guiyang 550002, China \\ ${ }^{*}$ Corresponding author \\ e-mail:534012813@qq.com
}

(Received $3^{\text {rd }}$ May 2019; accepted $11^{\text {th }}$ Jul 2019)

\begin{abstract}
Climate change causes drought and rainstorm, two extreme hydrological events, to occur interlock, and in a short period of time the rapid transformation of drought and flood disasters, resulting in more difficult rescue and relief, agricultural losses more serious. In order to study the characteristics of drought and flood in tobacco growing period in Xingren County. By defining the Long-cycle DroughtFlood Abrupt Alternation Index (LDFAI) and Short-cycle Drought-Flood Abrupt Alternation Index (SDFAI), the moving average method and precipitation anomaly are used. For the daily precipitation data during the tobacco growth period (5 8 months) from 1961 to 2012 in Xingren County, A comprehensive analysis of the (LDFAI SDFAI) change trends and monthly precipitation changes during the growth period of tobacco. The characteristics of rapid change of drought and flood in tobacco growing period were identified. The results showed that: the LDFAI in the tobacco growth period are mainly from drought to flood. In the future, there will be an increasing trend from flood to drought, and the strength is reduced; The trend of SDFAI is: increase-decrease-decrease; there is an increasing trend from drought to flood events in May-June; June-July is a period of drought-flood abrupt alternation, and the intensity is higher. In July-August, the flood to drought event has a decreasing trend and the intensity is reduced. During the tobacco maturity period, Monthly average precipitation is higher, the precipitation fluctuates greatly, Extremely prone to Drought-Flood Abrupt Alternation. The research results can provide theoretical basis for the formulation of countermeasures for disaster prevention and mitigation in Xingren County in China.
\end{abstract}

Keywords: climate change, drought-flood abrupt alternation, moving average method, precipitation anomaly method, tobacco growth period, Xingren County

\section{Introduction}

The Fifth Assessment Report of the Intergovernmental Panel on Climate Change (IPCC, 2013) points out that global warming has become an indisputable fact. Affected by climate change, extreme hydrological events present with the special complex phenomenon of flood and drought. Xingren County experienced the worst drought in 100 years in 2010. It lasted from August of the previous year to April. It lasted for 9 months and the soil moisture was extremely poor, which seriously affected tobacco seedlings and transplanting. The drought-flood abrupt alternation is a meteorological and hydrological event in which there is no rainfall or less rainfall in the early period, followed by high intensity rainfall and flood disaster in the short term, with the superimposed losses of drought and flood disasters in the region (Huang, 2015). Climate change causes two extreme hydrological events, drought and floods, which occur alternately and change rapidly in a short period of time to form a drought-flood disaster, which makes it more difficult to rescue and causes more serious losses on 
social economy and the people's production and life. It has a significant and farreaching impact on agricultural production and food security, water resources security, and ecological environment security (Niu et al., 2013). In 2010, drought and drought caused a loss of 50,000 tons of Xingren Tobacco and an economic loss of 60 million yuanRMB.

At present, foreign scholars mainly focus on the extreme hydrological events. Vogel (1978) studied the climate causes of abnormal precipitation in St. Louis; Ting et al. (1997) studied the variation of summer precipitation in the United States and its relationship with the Pacific SST. Domestic studies mainly focus on the causes for the change between drought and flood ( $\mathrm{Li}$ et al., 2014), the analysis of the law on the drought-flood abrupt alternation (Shen et al., 2012; Sun et al., 2012) and the impact of the drought-flood abrupt alternation on rice and peanut yield in the Yangtze River Basin (Yuan et al., 2008; Zhou et al., 2012). However, there are few reports on the droughtflood abrupt alternation in a short time scale and the disaster caused by the droughtflood abrupt alternation in tobacco growth period. Drought seriously affects the growth and development of flue-cured tobacco and the accumulation of dry matter. Excessive soil moisture is not conducive to tobacco growth and reduces the biomass of tobacco plants. In fact, Xingren County is one of the main tobacco growth areas in China, and also one of the prone areas to drought and flood disasters. Drought and flood disasters mainly occur in May to August, which has a greater impact on tobacco planting.

In view of this, according to the daily precipitation data from May to August at the meteorological station in Xingren County from 1961 to 2012, this study uses the precipitation anomaly percentage, the long-period drought-flood abrupt alternation index and the short-period drought-flood abrupt alternation index to systematically analyze the evolution characteristics of drought-flood abrupt alternation time in the tobacco growth period in this area, so as to provide reference for tobacco cultivation, flood control and drought relief.

Xingren County is located in QianXiNa buyi and miao minority autonomous prefecture is located in east longitude $104^{\circ} 54^{\prime}-105^{\circ} 34^{\prime}$, north latitude $25^{\circ} 16^{\prime}$ to $25^{\circ} 47^{\prime}$ in Guizhou, China, Figure 1.
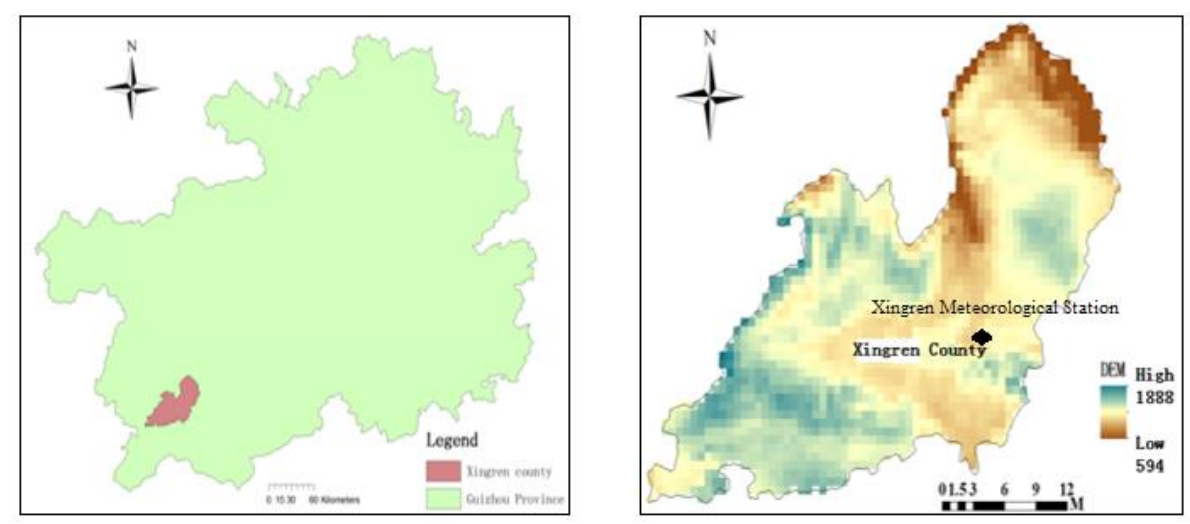

Figure 1. Overview of the research area

It is a low-latitude plateau temperate and humid monsoon climate region in midsubtropical zone. There is no severe cold in winter and no intense heat in summer. The frost-free period is longer, the rain and heat is in the same season, the annual average 
temperature is $15.2^{\circ} \mathrm{C}$, the annual rainfall is $1,315.3 \mathrm{~mm}$, and the annual accumulated temperature of $10.0{ }^{\circ} \mathrm{C}$ is $4,588.0{ }^{\circ} \mathrm{C}$. Superior light, heat, water and other climatic conditions make the county a suitable flue-cured tobacco growth areas. However, drought, hail, flood and other disasters seriously affect the yield and quality of fluecured tobacco (Xiao and Cui, 2014).

\section{Materials and methods}

\section{Data source}

The data used in the analysis of drought-flood abrupt alternation events are the daily precipitation data of Xingren National Reference Meteorological Station from 1961 to 2012, which are provided by the National Meteorological Information Center in China. Xingren National Reference Meteorological Station is located in east longitude $105^{\circ} 11^{\prime}$, north latitude $25^{\circ} 26^{\prime}$.

\section{Research method}

Precipitation anomaly percentage $(\mathrm{Pa})$

The precipitation anomaly percentage reflects the deviation degree of precipitation from the average state at a certain period of time, and its calculation formula is as follows (Guizhou Provincial Bureau of quality and Technology Supervision, 2015).

$$
P a=\frac{P-\bar{P}}{\bar{P}} \times 100 \%
$$

where, $P$ precipitation for a certain period of time, $m m ; \bar{P}$ annual mean precipitation at a certain period of time, $\mathrm{mm}$.

For the classification of drought and flood grades, refer to the monthly scale classification standard in DB52/T1030-2015 Drought Standard of Guizhou Province, as shown in Table 1.

Table 1. Classification of drought and flood grades by precipitation anomaly percentage (unit: \%)

\begin{tabular}{c|c|c|c}
\hline Type of drought & Pa & Type of flood & Pa \\
\hline Extraordinary & $\mathrm{Pa} \leq-95$ & Light & $40 \leq \mathrm{Pa}<60$ \\
Severe & $-95<\mathrm{Pa} \leq-80$ & Moderate & $60 \leq \mathrm{Pa}<80$ \\
Moderate & $-80<\mathrm{Pa} \leq-60$ & Severe & $80 \leq \mathrm{Pa}<95$ \\
Light & $-60<\mathrm{Pa} \leq-40$ & Extraordinary & $95 \leq \mathrm{Pa}$ \\
Normal & $-40<\mathrm{Pa}<40$ & & \\
\hline
\end{tabular}

\section{Long-period drought-flood abrupt alternation index in tobacco growth period}

The time scale of drought-flood change is defined as two months, that's, drought in May-June and flood in July-August, which is called drought-flood, and vice versa. There is no standard definition for the drought-flood abrupt alternation index. This paper refers to the definition of the drought-flood abrupt alternation index proposed by Wu et al. (2006) on the Yangtze River Basin, and adjusts the weight coefficient. 
a) Standardization of precipitation

$$
R=\frac{P_{i}-\bar{P}}{\sqrt{\frac{1}{N} \sum_{i=1}^{N}\left(P_{i}-\bar{P}\right)^{2}}}
$$

where $R$ - standardized precipitation; $P_{i^{-}}$original value of precipitation, $m m ; i=1,2$, $3, \ldots ., N ; \bar{P}$ - Average precipitation, $\mathrm{mm} ; \mathrm{N}$ - The total number of samples.

b) $L D F A I$

$$
L D F A I=\left(R_{78}-R_{56}\right) \times\left(\left|R_{56}\right|+\left|R_{78}\right|\right) \times 2^{-\left|R_{56}+R_{78}\right|}
$$

where, $R_{78^{-}}$Standardized precipitation from July to August; $R_{56^{-}}$Standardized precipitation from May to June; $R_{78}-R_{56^{-}}$The intensity of drought-flood abrupt alternation; $\left|R_{j}\right|+\left|R_{i}\right|$ - Intensity term of drought-flood abrupt alternation; $2^{-\mid R_{56}+R_{78} I}$ is weight coefficient, which functions to increase the weight of drought-flood abrupt alternation events and reduce the weight of all-drought or total-flood event. The criteria for judging the drought-flood abrupt alternation are as follows: if $L D F A I$ is great than 1, it's drought-flood event; if $L D F A I$ is less than 1, it's the flood-drought event; if $L D F A I$ is in the middle, it's normal; the absolute value of $L D F A I$ reflects the intensity of the drought-flood abrupt alternation, the greater the absolute value is, the more serious the drought and flood rapid change event is (Shan et al., 2015).

Short-term drought-flood abrupt alternation index during the tobacco growth period

The calculation method of SDFAI is basically the same as that of LDFAI, with the formula is (Wu et al., 2006)

$$
S D F A I=\left(R_{j}-R_{i}\right) \times\left(\left|R_{i}\right|+\left|R_{j}\right|\right) \times 3.2^{-\left|R_{i}+R_{j}\right|}
$$

where $R_{j}$ - Standardized precipitation in the $j$-th month; $R_{i}$ - Standardized precipitation in the $i$-th month; $R_{j}-R_{i^{-}}$The intensity of drought-flood abrupt alternation; $\left|R_{j}\right|+\left|R_{i}\right|-$ The intensity item of drought-flood abrupt alternation; 3.2 $2^{-\left|R_{i}+R_{j}\right|}$ - Weight coefficient; $\mathrm{j}=\mathrm{i}+1(\mathrm{i}=5,6,7)$.

\section{Non-uniformity of precipitation distribution}

The non-uniformity of precipitation distribution is studied and analyzed by using the non-uniformity and coefficient of rainfall distribution. The formula is as follows:

$$
\begin{gathered}
C_{V}=\frac{\sigma}{\bar{P}} \\
\sigma=\sqrt{\frac{1}{N} \sum_{i=1}^{N}\left(P_{i}-\bar{P}\right)^{2}}
\end{gathered}
$$


where $\sigma$ - Mean square error; $\bar{P}$ - Average precipitation over the same period of years, $m m ; P_{i^{-}}$Rainfall in the $i$-th year, $m m$.

\section{Results and analysis}

\section{Trend of long-term drought-flood abrupt alternation}

\section{Characteristics of typical long-term drought-flood abrupt alternation}

According to the precipitation sequence during the tobacco growth period in Xingren County, the Pa value and LDFAI value from May to June and from July to August from 1961 to 2012 are calculated by the Eq.1 to Eq.3. Table 2 lists the years with the highest (lowest) LDFAI values from 1961 to 2012 and its Pa value from May to June and from July to August by the Eq.1 to Eq.3.

Table 2. Six highest (lowest) LDFAI values and its Pa value from 1961 to 2012

\begin{tabular}{c|c|c|c|c|c|c|c}
\hline \multirow{2}{*}{ Year } & \multicolumn{3}{|c|}{ Highest (LDFAI) } & \multirow{2}{*}{ Year } & \multicolumn{3}{c}{ Lower (LDFAI) } \\
\cline { 2 - 4 } & LDFAI & May-June Pa/\% & July-August Pa/\% & & LDFAI & May-June Pa/\% & July-August Pa/\% \\
\hline 1999 & 9.73 & -40.84 & 67.40 & 1978 & -3.14 & 43.92 & -26.46 \\
1986 & 8.12 & -37.24 & 68.54 & 1972 & -3.04 & 18.96 & -59.52 \\
1988 & 3.33 & -46.93 & 27.60 & 1966 & -1.94 & 21.76 & -22.59 \\
1970 & 3.00 & -39.41 & 25.99 & 1974 & -1.80 & 24.40 & -20.17 \\
2004 & 2.92 & -39.07 & 25.51 & 1962 & -1.54 & 16.05 & -21.63 \\
1961 & 1.96 & -42.05 & 16.25 & 1994 & -1.39 & 15.33 & -20.52 \\
\hline
\end{tabular}

It can be seen that in the years with higher $L D F A I$, the precipitation in from May to June is less (35\%), and drought event occurs, and the precipitation from July to August is more (15\%), and flood event occurs, so the drought-to-flood event is formed. From May to June in 1999 , the precipitation generally decreased by $40.84 \%$, belonging to light drought event, but from July to August in 1999, the precipitation generally increased by $67.40 \%$, and moderate flood occurs, with LDFAI as high as 9.73, belonging to typical drought-flood event. In the years with lower LDFAI, the precipitation from May to June is more (15\%), which belongs to flood event, and from July to August, the precipitation is less (20\%), which leads to the drought event, so the flood-to-drought event occurs. The precipitation from May to June in 1978 is more $(43.92 \%)$ and the light flood occurs; the precipitation from July to August is less $(26.46 \%)$ and the drought occurs, with the $L D F A I$ of -3.14 , belonging to typical floodto-drought event. Therefore, $L D F A I$ can reflect the phenomenon of drought-flood abrupt alternation to a certain extent.

\section{Interannual trend of long-term drought-flood abrupt alternation}

Figure 2 depicts that interannual change of LDFAI from 1961 to 2012. It can be seen from the figure that most of LDFAIs are positive, indicating that the long-term droughtflood abrupt alternation in Xingren County is mainly drought-to-flood. LDFAI fluctuated more frequently from the end of 1960s to the end of 1970s, which indicates that there are more drought-flood abrupt alternations from the end of 1960s to the end of 1970s. LDFAI appeared two anomalously large in the early 1980s and the end of 1990s, 
mainly due to two high intensity drought-to-flood events. According to the 3 a moving average curve and 5a moving average curve, the occurrence frequency and intensity of the long-term drought-flood abrupt alternation events are decreasing.

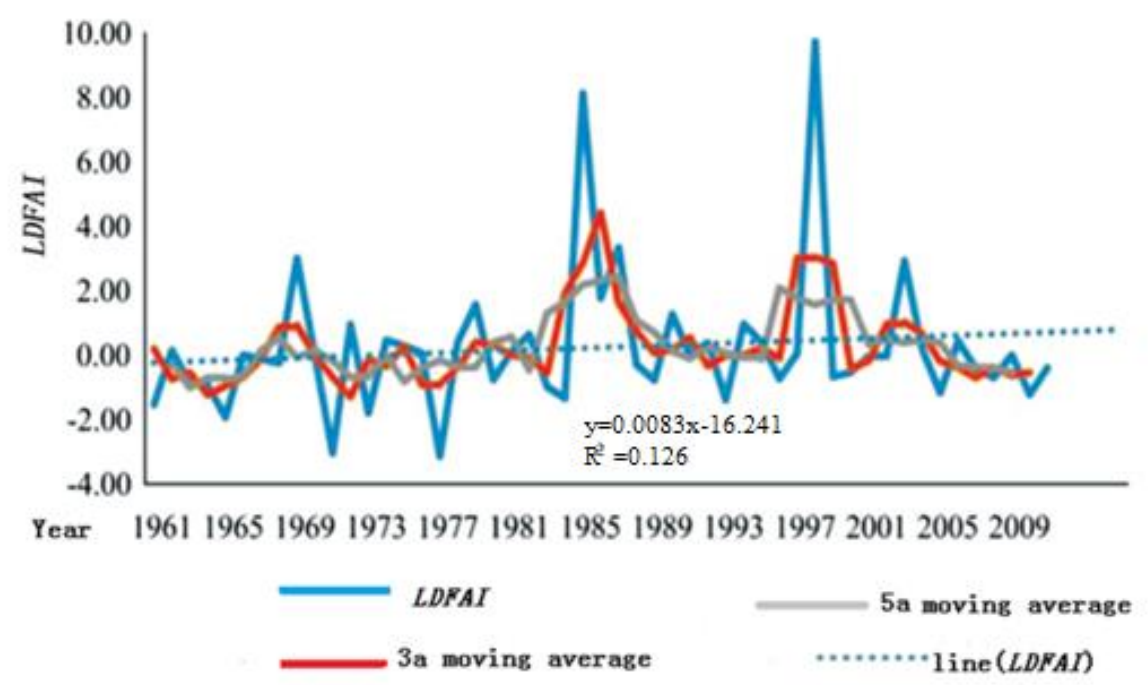

Figure 2. Trend of the long-term drought-flood abrupt alternation in the tobacco growth period in Xingren County

\section{Trend of the short-term drought-flood abrupt alternation}

\section{Characteristics of typical short-term drought-flood abrupt alternation}

According to the precipitation sequence during the tobacco growth period in Xingren County, the short-period drought-flood abrupt alternation index in the tobacco growth period from 1961 to 2012 is calculated by the Eq.4 to Eq.6. Tables 3, 4 and 5 show $S D F A I$ and its $P a$ values of the typical drought-flood abrupt alternation years from 1961 to 2012 .

Table 3. SDFAI and characteristics of drought-flood from May to June in Xingren County

\begin{tabular}{c|c|c|c|c}
\hline Year & May Pa/\% & June Pa/\% & SDFAI & Type \\
\hline 1979 & -42.51 & 55.95 & 3.66 & Light drought to light flood \\
1980 & 43.12 & -46.29 & -4.10 & Light flood to light drought \\
1991 & -74.88 & 41.74 & 3.86 & Moderate drought to light flood \\
2007 & -51.48 & 60.33 & 5.26 & Light drought to light flood \\
2008 & 132.14 & -45.31 & -1.96 & Extraordinary flood to light drought \\
2011 & -73.16 & 49.36 & 5.72 & Moderate drought to light flood \\
\hline
\end{tabular}

Table 4. SDFAI and characteristics of drought-flood from June to July in Xingren County

\begin{tabular}{c|c|c|c|c}
\hline Year & June Pa/\% & July Pa/\% & SDFAI & Type \\
\hline 1965 & 58.94 & -39.84 & -4.75 & Light flood to light drought \\
1970 & -51.57 & 74.17 & 6.40 & Light drought to moderate flood \\
1980 & -46.29 & 44.61 & 1.80 & Light drought to light flood \\
1999 & -68.08 & 86.77 & 8.44 & Moderate drought to serious flood \\
2004 & -43.70 & 51.29 & 2.49 & Light drought to light flood \\
2011 & 49.36 & -63.01 & -5.97 & Light flood to moderate drought \\
\hline
\end{tabular}


Table 5. SDFAI and characteristics of drought-flood from July to August in Xingren County

\begin{tabular}{c|c|c|c|c}
\hline Year & July Pa/\% & August Pa/\% & SDFAI & Type \\
\hline 1965 & -39.84 & 50.18 & 2.92 & Light drought to light flood \\
1977 & 80.18 & -48.13 & -3.54 & Serious flood to light drought \\
1988 & -40.97 & 110.08 & 1.84 & Light drought to extraordinary flood \\
1997 & 69.66 & -46.07 & -3.57 & Moderate flood to light drought \\
2002 & -54.83 & 65.70 & 5.12 & Light drought to moderate flood \\
\hline
\end{tabular}

The comparison shows that SDFAI is mainly positive from May to June, mainly from light and moderate drought to light flood, with the only event from extraordinary flood to light drought in 2008. SDFAI is higher from May to June, which indicates that the intensity of drought-flood abrupt alternation events is higher in this period and the period when drought-flood abrupt alternation events are prone to occur. From July to August, SDFAI is low, which indicates that the intensity of drought-flood abrupt alternation events is decreased and the number of drought-flood abrupt alternation events is decreased. From May to June of 1980, the light flood to light drought occurred, but from June to July of 1980, the light drought to light flood occurred again, the drought and flood occurred frequently in a year, and it is the tobacco flourishing period (Qiu et al., 2013), so we should guard against the adverse effects brought by the drought-flood abrupt alternation.

\section{Interannual trend of short-term drought-flood abrupt alternation}

Figure 3 depicts the interannual change of SDFAI from 1961 to 2012. Through the analysis, we can conclude that the short-term drought-flood abrupt alternation has the following characteristics in the tobacco growth period.

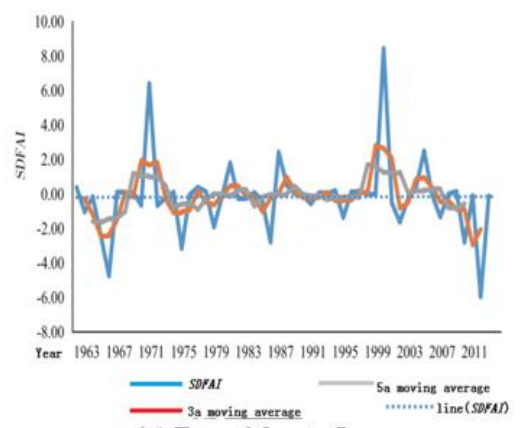

(a) From May to June
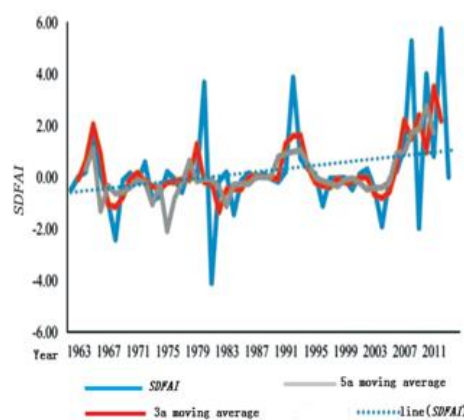

(b) From June to July

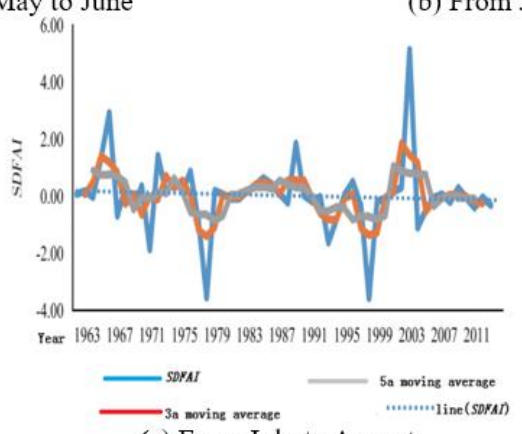

(c) From July to August

Figure 3. Trend of the short-term drought-flood abrupt alternation in the tobacco growth period in Xingren County 
a) From May to June mainly occurs the drought-to-flood; SDFAI oscillated frequently and violently after the 21 st century. The drought-to-flood events with higher intensity mainly occurred after the 21 st century, the flood-to-drought events with higher intensity mainly occurred before 1980s, and only two drought-to-flood events with higher intensity occurred after 1980s. From 3a moving average curve, 5a moving average curve and SDFAI trend curve, it can be seen that the drought-to-flood events have an increasing trend, which is obvious.

b) From June to July mainly occurs the flood-to-drought; SDFAI oscillated frequently from the beginning of 1960s to the beginning of 1980s. The drought-to-flood events with higher intensity mainly occurred after 1990s, and only one drought-to-flood event with higher intensity occurred in 1960s. From 3a moving average curve, 5a moving average curve and SDFAI trend curve, it can be seen that the flood-to-drought events have a slight increasing trend.

c) From July to August mainly occurs the flood-to-drought; SDFAI oscillated frequently from the beginning of 1960s to the beginning of 1980s. The drought-to-flood events with higher intensity mainly occurred after 1990s and only one drought-to-flood event with higher intensity occurred in 2002 after entering the 21 st century, without any drought-to-flood event event afterwards. From 3a moving average curve, 5a moving average curve and SDFAI trend curve, it can be seen that the flood-to-drought events have a slight increasing trend.

\section{Changes of monthly precipitation during tobacco growth period}

The maximum, minimum, average and non-uniform coefficient of monthly precipitation distribution during the tobacco growth period from 1961 to 2012 in Xingren County are analyzed. The calculation results are shown in Table 6.

Table 6. Statistics on monthly precipitation characteristic amount of 52 a tobacco growth period in Xingren County

\begin{tabular}{|c|c|c|c|c|c|c|c|}
\hline \multirow{2}{*}{ Month } & \multicolumn{2}{|c|}{$\begin{array}{c}\text { Maximum } \\
\text { precipitation }\end{array}$} & \multicolumn{2}{|c|}{$\begin{array}{c}\text { Minimum } \\
\text { precipitation }\end{array}$} & \multirow{2}{*}{$\begin{array}{l}\text { Monthly average precipitation } \\
\text { in tobacco growth period }\end{array}$} & \multirow{2}{*}{$C_{V, M}$} & \multirow{2}{*}{$\begin{array}{l}\text { Annual extreme ratio } \\
\text { of monthly rainfall }\end{array}$} \\
\hline & Year & $\begin{array}{l}\text { Precipitation } \\
(\mathbf{m m})\end{array}$ & Year & $\begin{array}{l}\text { Precipitation } \\
(\mathbf{m m})\end{array}$ & & & \\
\hline 5 & 2008 & 390.9 & 2011 & 45.2 & 168.39 & 0.42 & 8.65 \\
\hline 6 & 2006 & 480.4 & 1961 & 81.4 & 274.44 & 0.37 & 5.90 \\
\hline 7 & 1987 & 474.3 & 1972 & 57.1 & 239.54 & 0.46 & 8.31 \\
\hline 8 & 1988 & 418.4 & 2011 & 26.2 & 199.16 & 0.46 & 15.97 \\
\hline
\end{tabular}

As can be seen from Table 6, the precipitation in Xingren County increased firstly and then decreased during tobacco growth period, among which the maximum precipitation, the minimum precipitation and the maximum of monthly average precipitation are all in June, indicating that the precipitation in June is more and June is prone to flood disasters; the annual extreme value ratio of monthly precipitation is also smaller in June, and the value of $C_{V, M}$ is also smaller in June, indicating that the monthly precipitation fluctuation is small. The value of $C_{V, M}$ is larger in August and the annual extreme value ratio of monthly precipitation is the largest in August, which indicates that precipitation fluctuates greatly in this period and drought-flood abrupt alternation events are easy to occur. 


\section{Discussion}

The growth period of spring tobacco in the field is from May to August, including root elongation period (30-35 d), flourishing period (30 d) and mature period (60-65 d) (Tang, 2011). In the growth period of spring tobacco in the field, the precipitation is suitable in the range of $400 \sim 520 \mathrm{~mm}$, the monthly average water requirement is about $100 \mathrm{~mm}$ at the elongation period, about $200 \mathrm{~mm}$ at the flourishing period is and about $100 \mathrm{~mm}$ at maturity period (Ran et al., 2010). In May, which is the elongation period, the monthly rainfall could meet the needs of tobacco growth, moderate water shortage could promote root development, and excessive water would lead to root necrosis. Due to the increasing trend of short-term drought-to-flood events, irrigation and drainage work should be done well to ensure the survival rate of tobacco seedlings. In June, when tobacco is flourishing, the monthly average rainfall can meet the demand of tobacco growth, and with small fluctuation of rainfall, drought and flood events are not easy to occur, but the drought-flood abrupt alternation events with high intensity are easy to occur in this stage, so the precautions are required. July to August is the maturity period of tobacco, the precipitation fluctuates greatly, and the monthly average rainfall is relatively large. The excessive rainfall may cause the tobacco leaves to be too thin to modulate, low nicotine content and the insipid aroma. The mature tobacco leaves should be picked in time according to the forecast situation of the meteorological department, with the efforts made in the drainage of tobacco fields to ensure the quality of tobacco leaves.

\section{Mechanism of the drought-flood abrupt alternation}

Xingren County belongs to the typical monsoon climate fragile area, and the monsoon change causes the uneven annual precipitation distribution. What's more, the local is of the karst landform, and with strong water permeability and poor water retention, so it's extremely easy to suffer from the drought. In addition, the abnormal atmospheric circulation over the Qinghai-Xizang Plateau results in the formation of cold and high-pressure air masses in the plateau, which block the warm and humid air flow from the Indian Ocean and the Bay of Bengal. However, it's not easy for the cold air from the north to reach the area and it's difficult for the cold and warm air flows to intersect to form precipitation. The water vapor producing strong precipitation mainly comes from the South China Sea and the Bay of Bengal in the northern Indian Ocean (Sun et al., 2017). In summer, the southwest monsoon intensifies, and the transported water vapor increases. When cold air intrudes, the cold and warm air flows converge, resulting in relatively strong precipitation, resulting in drought-flood abrupt alternation. Another factor that produces strong precipitation in a short period of time is that the topographic relief within the territory is large, and the topography is high in the west and low in the east; blocked by the topography, during the day, the foot of the mountain, receives less solar radiation, air heating is not as fast as the top of the mountain, leading to heat air on the mountain top, floating in the sky; the air at the foot of the mountain, is cold and the atmosphere is relatively stable. At night, the temperature at the top of the mountain drops faster than that at the foot of the mountain, and the air sinks after cooling, raising the warm and humid air at the foot of the mountain. As the air rises, the water vapor cools down continuously, resulting in heavy rainfall and a sharp drought-toflood. 


\section{Conclusions}

The main conclusions are as follows:

(a) During the tobacco growth period in Xingren County, the long-term droughtflood abrupt alternation is dominant, and the frequency of the 1 long-term drought-flood abrupt alternation events generally decreases. In the 21 st century, the trend of flood-todrought events increases and the intensity decreases.

(b) The evolution trend of short-term drought-to-flood events during the tobacco growth period in Xingren County is as follows: increase-decrease-decrease; and the increasing trend is obvious, which is identical with the change trend of short-term drought-to-flood events. From May to June, the drought-to-flood increases; from June to July, it's easy to suffer from the drought-to-flood rapid change, with the relatively high intensity, and then at the transition period of tobacco from flourishing to maturing period, excessive or insufficient water should be prevented from to avoid the decline in tobacco yield and quality; from July to August, the flood-to-drought has a increasing trend, with the increasing intensity, and it's the tobacco maturity period, it's necessary to prevent tobacco quality from deteriorating due to the drought-flood abrupt alternation.

(c) In the tobacco flourishing period, the monthly average precipitation is the most and the fluctuation of precipitation is the least, so the flood disaster is very easy to happen. In the tobacco maturity period, the monthly average precipitation is more and precipitation fluctuation is greater, so it's extremely prone to drought-flood abrupt alternation and we should take precautions.

Acknowledgements. This paper is funded by the Water Conservancy Research Project of Guizhou Provincial Water Resources Department (Grant No.: KT201705) and National Natural Science Foundation (Grant No.: 51779093).

\section{REFERENCES}

[1] Guizhou Provincial Bureau of quality and Technology Supervision (2015): Guizhou drought standard DB52/T1030-2015.

[2] Huang, R. (2015): Research on evolution and Countermeasures of drought-floods abrupt alternation events in Huaihe River basin. - China Institute of Water Resources \& Hydropower Research, Beijing.

[3] IPCC. Climate Change (2013): The Physical Science Basis, Contribution of Working Group I to the Fifth Assessment Report of the Inter-governmental Panel on Climate Change. - Cambridge, United Kingdom and New York, NY, USA: Cambridge University Press, 2013.

[4] Li, X., Yuan, D. M., Yin, Z. C. Li, W. J., Xie, Z. (2014): Preliminary Analysis of Sudden Turn of Drought and Flood in the Middle and Lower Reaches of the Yang. - Climatic and Environmental Research 19(1): 41-50.

[5] Niu, J. L., He, Z. Y., Zhang, T. Y., Chen, X. Y. (2013): Impacts of Sudden Drought to Flood Change on Manufacture Livelihood and Ecology. - Resources and environment in the Yangtze River Basin 22(Z1): 108-115.

[6] Qiu, X. B., Yin, P. D., Chen, W., Ding, F. Z., Liang, G. L., Li, J. W., Pan, W. J. (2013): Effect of Climate Change on Transplanting Time of Flue-cured Tobacco in Zunyi County during 51 Years. - Chinese Tobacco Science 34(4): 36-41.

[7] Ran, F. F., Wang, H. T., Xun, Z. C., Wang, M., Hu, H. Y. (2010): Changes of climate and comprehensive evaluation of climate feasibility Under different transplanting dates in 
Xuchang tobacco-growing areas. - Journal of Henan Agricultural University 44(2): 217223.

[8] Shan, L. J., Zhang, L. P., Chen, X. C., Yang, W. (2015): Spatio-temporal Evolution characteristics of Drought-Flood abrupt alternation in the Middle and Lower reaches of the Yangtze River Basin. - Resources and Environment tin the Yangtze Basin 24(12): 2100-2107.

[9] Shen, B. Z., Zhang, S. X., Yang, H. W., Wang, K., Feng, G. L. (2012): Analysis of characteristics of a sharp turn from drought to flood in the middle and lower reaches of the Yangtze River in spring and summer in 2011. - Acta Physica Sinica 61(10): 530-540.

[10] Sun, P., Liu, C. L., Zhang, Q. (2012): Spatio-temporal variations of drought -flood abrupt alternation during main flood season in East River Basin. - Pearl River 33(5): 29-34.

[11] Sun, X. T., Li, Q. Q.,Wang, L. J. (2017): Characteristics of Long-Cycle Abrupt DroughtFlood Alternations in Southwest China and Anomalies of Atmospheric Circulation in Summer. - Chinese Journal of Atmospheric Sciences 41(6): 1332-1342.

[12] Tang, S. K. (2011): The environment of tobacco growth. - Yun Yunnan Science and Technology Publishing Press.

[13] Ting, M. F., Wang, H., Summertime, U. S. (1997): Precipitation variability and its relation to Pacific sea surface temperature. - Journal of Climate 10: 1853-1873.

[14] Vogel, J. L., Huff, F. A. (1978): Relation between St-Louis Urban Precipitation Anomaly and Synoptic Weather Factors. - Journal Of Applied Meteorology 17(8): 1141-1152.

[15] Wu, Z. W., Li, J. P., He, J. H., Jiang, Z. H. (2006): Large-Scale Atmospheric Circulation anomaly and long period drought and Flood in the Middle and Lower reaches of the Yangtze River in Summer. - Chinese Science Bulletin (14): 1717-1724.

[16] Xiao, W., Cui, T. (2014): Study on the Climate conditions of developing Flue-cured Tobacco planting in Xingren County, Guizhou Province. - Beijing Agriculture 198-200.

[17] Yuan, J., Jiang, X. H., Huang, J. Z., Zhang, E. Z. (2008): Effects of Fast Conversion from Drought to Waterlogging Stress on Physiological Characteristics of Rice in Jointingbooting Stage. - Water Conservancy Science and Technology and Economy 2008(4): 259-262.

[18] Zhou, X., Li, L., Shan, S. H. (2012): Effect of abrupt droughts-floods on physiology and biochemistry of different peanut varieties. - Chinese Journal of Oil Crop Sciences 34(1): 56-61. 